\title{
Folic acid-containing nanofibers by simultaneous process for transdermal drug delivery: preparation, characterization, and in vitro biocompatibility
}

\section{Fatma Nur Parın}

Bursa Technical University https://orcid.org/0000-0003-2048-2951

Çiğdem İnci Aydemir

Bursa Technical University

Gökçe Taner

Bursa Technical University

Kenan Yıldırım ( $\square$ kenan.yildirim@btu.edu.tr)

Bursa Technical University

\section{Research Article}

Keywords: drug release, electrospinning, electrospraying, nanofiber, folic acid, cytotoxicity

Posted Date: June 11th, 2020

DOI: https://doi.org/10.21203/rs.3.rs-33973/v1

License: (c) (i) This work is licensed under a Creative Commons Attribution 4.0 International License. Read Full License 


\section{Abstract}

Nanofibers with bioactive agents are good candidates for skin-care applications due to high spesific surface area, low density and highly porous structure. In this study, hydrophilic based bioactive nanofibers were produced via an electrospinning and electrospraying simultaneous process. Polyvinyl alcohol (PVA), polyvinyl alcohol-gelatin (PVA-Gel) and polyvinyl alcohol-alginate (PVA-Alg) polymers were used as the matrix material and folic acid (FA) particles were dispersed simultaneously on the surface of these hydrophilic nanofibers. The morphology of the nanofibers (NFs) was uniform and dispersed folic acid particles incorporated into the structure of nanofibers as confirmed by scanning electron microscopy (SEM). Thermal behavior, chemical structure of the composite nanofibers were analyzed/investigated by thermogravimetric analysis (TGA) and Attenuated Total Reflectance-Fourier Transform Infrared Spectroscopy (ATR-FTIR) which showed that no chemical bonding between vitamin and polymers. A controlled release of FA-loaded electrospun fibers were carried out by UV-Vis in vitro study within the 8 hour-period in artificial sweat solutions (acidic media, pH 5,44). The obtained PVA/FA, PVA-Gel/FA and PVA-Alg/FA fibers released $49.6 \%, 69.55 \%$ and $50.88 \%$ of the sprayed FA in $8 \mathrm{~h}$, indicating the influence of polymer matrix and polymer-drug interactions, on its release from the polymer matrix. Moreover, biocompatibility of all developed novel NFs was assessed by two different cytotoxicity tests,3-(4,5dimethylthiazol-2-yl)-2,5-diphenyltetrazolium bromide (MTT) assay and neutral red uptake (NRU) assay in L929 cell lines. In all cases, it is clearly concluded that these new electrospun fibers had fast-release of the vitamin and the hybrid process is suitable for transdermal patch applications, especially for skin-care products. Moreover, it has been proposed nanofiber with folic acid as a patch may prevent the COVID-19. The results of cytotoxicity assays on L929 cell reveal that all prepared NFs have no or slight cell toxicity. PVA and PVA-Gel with/without FA nanofibers seems more biocompatible than PVA-Alg nanofibers.

\section{Introduction}

Human skin, the largest organ in the body, has vital functional role by protecting from pollution, ultraviolet radiation and other damage, which cause to skin aging and disorders [1-3]. Skin has well-organized morphological structure and self-renewing barrier property. It comprises of three multilayers structure with different levels of cellular and epidermal differentiations that serves as a protective barrier $[4,5]$. The outmost layer of the skin is epidermis known as the stratum corneum (SC) contains dead cells (corneocytes) interdispersed within a greasy matrix $[1,2,6]$. Therefore, SC provides selective permeability and limits hydrophilic rich compounds to penetrate in to the inner layers. Transportation process of many bioactive materials in skin is mainly resulted by passive diffusion [7] in related to Fick's Law [8]. (Ficks Law summarized the absorption model in skin)

Transdermal drug delivery system (TDDS) is defined as pharmaceutical ingredients are transported locally or systemically via skin $[1,9,10]$. The approach is alternative to oral, intravascular, subcutaneous, and transmucosal routes due to loss of effectiveness and toxicity of drugs (degradation) [11,12]. Besides, TDDS have not cause painful administration and other unwanted side effects on the gastrointestinal tract compared with oral or injection administration, especially. Therefore, this route has not damage to 
liver. However, the penetration of drugs via SC has many limitations. It is known that drug molecules penetrate/pass through/ via SC by two routes including intercellular (hydrophilic drugs) and intracellular (hydrophobic drugs) mechanisms. A drug molecule needs some physicochemical properties such as sufficient hydrophobicity, high and sufficient partition coefficient (Log P 1-3), low molecular weight ( $<500$ $\mathrm{Da})$ and the short half life for better penetration $[1,13,14]$.

During the last decades, nanofibers have become excellent candidate for transdermal drug release applications due to high porosity, large spesific surface area and small size of electrospun fibers $[10,15]$. There have been many attemptions about pharmaceutical ingredients incorporated into nanofibers for usage of transdermal applications. In this regard, Galkina et al. (2013) reported cellulose NFs - titania nanocomposites grafted with three different drugs can be potential transdermal patch [16]. Gencturk et al. (2017) fabricated polyurethane/hydroxypropyl cellulose electrospun nanofibers with Donepezil (DNP) hydrochloride and in their study, controlled release of DNP from the fibers within $6 \mathrm{~h}$ was observed [17]. With the similar strategy, Esenturk et al. (2020) have investigated in vitro drug release behavior of voriconazole (VCZ) loaded hydrophilic PVA/SA electrospun NFs [18]. The obtained NFs indicated sustain release behavior with $8 \mathrm{~h}$. Also in a similar study reported by Shen et al. (2014) that prazosin Hydrochloride-loaded Poly(vinyl alcohol) fibers were prepared by conventional electrospinning, the resulting materials released drug with sustain behavior over the $24 \mathrm{~h}$ [19]. Kataria et al. (2014) developed transdermal patch based on ciprofloxacin loaded poly vinyl alcohol (PVA) and sodium alginate (NaAlg) electrospun composite nanofiber for wound healing [20]. These NFs showed cumulative drug release reached to about $99 \%$ after $24 \mathrm{~h}$. In another study, Tran et al. (2015) investigated release behavior of Ibuprofen from NFs. PCL, pNIPAM and pNIPAM/PCL were used as carriers of the drug for thermoresponsive transdermal delivery systems [21]. The release behavior of the fibers significantly changed with 4-hour period depending on the temperature. Song et al (2016) developed an alternative patch for the use of Daidzein in oral delivery applications [22]. The Daidzein-loaded PLGA fibers showed around $65.38 \%$ with sustained released behavior after $72 \mathrm{~h}$.

Furthermore, vitamin loaded NFs have received increasing attention as transdermal patches. Within this aim, Madhaiyan et al. (2013) synthesized vitamin B12-loaded polycaprolactone NFs and the resulting fibers indicated gradually vitamin release behavior in 48-hour period [23]. A slow release of the vitamin $E$ was observed from silk fibroin NFs over $72 \mathrm{~h}$ to utilize for skin care applications [24]. In another study, electrospun fibers made of gelatin was loaded with the vitamin $A$ and $E$ and investigated as wound healing patch [25]. The in vitro test results displayed the fibers have sustained release behavior for more than 60 hours.

Previous studies mainly focused on drug-loaded NFs fabricated by conventional electrospinning. Apart from electrospinning, there is one approach used in drug release applications which is called electrospraying. Electrospraying is sister technology of electrospinning to fabricate nanomaterials with < $1 \mu \mathrm{m}$ diameter [26]. In electrospinning, polymer solution concentration is sufficient to develop chain formation in the capillary by using high voltage potential while the polymer solution concentration is too low and droplets is spraying from the capillary in electrospraying [27]. However, nanoparticles 
micro/nanoparticle dispersions are processed with electrospraying due to low viscosity. There are many studies on nanofibers produced together with electrospinning and electrospraying process. However, to the best of our knowledge, there is no report on the transdermal drug delivery of nanofibers produced with simultaneous electrospinning and electrospraying process.

In the current study, electrospinning and electrospinning were performed simultaneously to fabricate the electrospun PVA, PVA-Gel and PVA-Alg fibrous mats. Folic acid utilized as model drug. By varying the polymer matrix type, the properties of as-spun/FA NFs were investigated in terms of morphology, thermal and chemical structure (polymer-polymer and polymer-drug compatibility). In vitro drug release from the NFs was assessed. The biocompatibility of the nanofibers was also evaluated through by 3-(4,5dimethylthiazol-2-yl)-2,5-diphenyltetrazolium bromide (MTT) and neutral red uptake (NRU) assayson the L929 cell lines (mouse fibroblasts) as recommended in IS010993-5 standard.

\section{Materials And Methods}

\subsection{Materials}

The Polyvinyl alcohol (PVA) (density $0.4-0.6 \mathrm{~g} / \mathrm{cm}^{3}$, purity $87.8 \%$ ) was purchased from ZAG Chemical (Turkey). Gelatine from bovine skin (225 Bloom, type B), Alginate and sodium bicarbonate $\left(\mathrm{NaHCO}_{3}\right)$ (99.7\% purity) and acetic acid $\left(\mathrm{CH}_{3} \mathrm{COOH}\right)$ with $80 \%$ purity obtained from Sigma Aldrich Chemical Company (USA) and ethanol (99.9\% purity, Tekkim). Folic acid $\left(\mathrm{C}_{19} \mathrm{H}_{19} \mathrm{~N}_{7} \mathrm{O}_{6}\right)$ for Biochemistry $(98-102 \%$ purity) was supplied from ChemSolute Company (Germany). To prepare the artificial sweat solutions, LHistidine monohydrochloride monohydrate $\left(\mathrm{C}_{6} \mathrm{H}_{9} \mathrm{O}_{2} \mathrm{~N}_{3} \cdot \mathrm{HCl} \cdot \mathrm{H}_{2} \mathrm{O}\right)$ ( $>99 \%$ purity), sodium chloride ( $>99.5$

purity) and sodium dihydrogen phosphate dihydrate $\left(\mathrm{NaH}_{2} \mathrm{PO}_{4} \cdot 2 \mathrm{H}_{2} \mathrm{O}\right)$ were purchased from Sigma Aldrich Chemical Company (USA). The chemicals used in the MTT and NRU assay tests: RPMI (Roswell Park Memorial Institute) 1640 medium, fetal bovine serum (FBS), penicillin-streptomycin, neutral red (NR) (3-amino-7-dimethyl-amino-2- methylphenazine hydrochloride), 3-(4,5-dimethylthiazol-2-yl)-2,5diphenyltetrazolium bromide (MTT), trypan blue, ethanol from Sigma; dimethyl sulfoxide (DMSO) from Merck; Triton X-100, trypsin-EDTA, Dulbecco's phosphate buffered saline (DPBS) from Gibco. Distilled water was used in the experiments and all of the reagents were used without any purification.

\subsection{Fabrication of Hybrid Nanofibers}

The hydrophilic based polymer/FA nanofibers were fabricated by combining electrospinning and electrospraying process (INOVENSO Nanospinner24, Turkey). PVA powders were dissolved in pure water at $90^{\circ} \mathrm{C}$ till a $10 \%(\mathrm{w} / \mathrm{w})$ homogeneous PVA solution was obtained. Gelatin was dissolved in pure water and acetic acid binary-solvent systems $(7: 3 \mathrm{w} / \mathrm{w})$ solution to obtain a $20 \%(\mathrm{w} / \mathrm{w})$ gelatine solution by stirring for 2 hours at ambient conditions. Alginate powders were also dissolved in water to obtain a $2 \%$ $(\mathrm{w} / \mathrm{w})$ alginate solution. PVA-alginate $(4: 1 \mathrm{v} / \mathrm{v})$ and PVA-gelatin solutions $(3: 2 \mathrm{v} / \mathrm{v})$ were mixed at room temperature for overnight. In our previous experiments, it was determined optimum folic acid (FA) concentration in electrospraying system. $22 \mathrm{mg}$ FA was dispersed in $10 \mathrm{ml}(2: 1 \mathrm{v} / \mathrm{v})$ pure water and 
alcohol solution for each polymer system via ultrasonic homogenizer (Bandelin/Sonoplus HD3200). Each polymer solution (PVA, PVA-gelatin and PVA-alginate) and FA particle dispersion were transferred into two seperate plastic syringes $(10 \mathrm{~mL})$ and put side to side on two syringe pumps. The plastic syringes were attached to two stainless steel nozzle. The PVA, PVA-gelatin and PVA-alginate solutions and FA dispersion were dispensed via nozzle which was vertical to the collecting plate. The feed rates were performed at $2 \mathrm{~mL} / \mathrm{h}$ and $1.5 \mathrm{~mL} / \mathrm{h}$ for polymers and FA dispersion, respectively. Neat PVA, PVA-gelatine and PVA-alginate solutions were prepared as a control (Fig. 1).

\subsection{Nanofiber Characterization}

\subsubsection{Scanning electron microscopy (SEM)}

Morphology of all nanofibers was observed with Carl Zeiss/Gemini 300 Scanning Electron Microscope (SEM) (ZEISS Ltd.,Germany). All samples were coated with gold for 20 minutes before analysis. Fiber diameters were measured using Image $\mathrm{J}$, version 1.520 software.

\subsubsection{Thermal Analysis (TGA)}

TA /SDT650 TGA(USA) were used for the thermal analysis. TGA analyses were performed under nitrogen atmosphere with $20^{\circ} \mathrm{C} \mathrm{min}-1$ heating rate and $30^{\circ} \mathrm{C}-600^{\circ} \mathrm{C}$ temperature range and applied oxygen atmosphere with $20^{\circ} \mathrm{C} \mathrm{min}-1$ heating rate $600^{\circ} \mathrm{C}-900^{\circ} \mathrm{C}$ temperature.

\subsubsection{Fourier transform infrared spectroscopy (FT-IR)}

FTIR data were obtained with a Thermo Nicolet iS50 FTIR (USA) spectrometer with a ATR (Attenuated Total Reflectance) adapter (Pike, USA) in the range of $4000-500 \mathrm{~cm}^{-1}$ recorded with 16 scans at $4 \mathrm{~cm}^{-1}$ resolutions.

\subsubsection{In vitro Release Study}

The pH of skin surface ranges from 4.2 and 5.6 [28]. Furthermore, solubility of folic acid as a drug is maximum at pH 5 to 6 [29]. Therefore, artificial sweat solutions were prepared according to ISO 105E04:2013 method [30]. The vitamin-release behavior of FA sprayed resulting fibers were studied in acidic sweat solutions at pH 5.44 by total immersion method [23]. $12-30 \mathrm{~cm}^{2}$ of the nanofibers were put into sealed glass tubes with each containing $50 \mathrm{~mL}$ of acidic sweat solution, separately. Then, they were placed in shaking incubator at $37.5^{\circ} \mathrm{C}$ with stirring $120 \mathrm{rpm}$ in order to apply the release profile of the folic acid. Samples of $3 \mathrm{ml}$ was removed at the specified time intervals with the sweat solution and the corresponding absorbance value was determined in a UV spectrophotometer (Scinco/NEOYSY 2000) at $\lambda_{\max }=282 \mathrm{~nm}$, which was the characteristic peak of folic acid. The drug concentration was obtained from the calibration curve of the model vitamin prepared with a folic acid solution of known concentrations in acidic solutions ( $\mathrm{pH}$ 5.44). The calibration curve was found to be $Y=0,0486 \mathrm{X}+$ $(-0,0402)\left(R^{2}=0,99992\right)$, where $X$ is the concentration of $F A(m g / L)$ and $Y$ is the solution absorbance at 
$282 \mathrm{~nm}$ (linear range of $0.5-25 \mathrm{mg} / \mathrm{L}$ ) (Fig. 2). The amount of released drug was determined using UVVis spectroscopy.

\subsubsection{In vitro biocompatibility}

\section{Preparation of nanofiber extract solutions for cytotoxicity assays}

In this study in order to determine the cytotoxic effects of novel NFs prepared in different compositions, extracts of all samples were prepared among the methods recommended by the UNI EN ISO 10993-12 : 2009 regulation [31] and also suitable for the nature and shape of NFs as biomaterials. Before performing the extraction procedure, equal sizes of NF patch samples $\left(3 \mathrm{~cm}^{2}\right)$ were cut and each sample was sterilized by UV light for 1 hour in order to keep the structural properties of the nanofibers intact. The extraction procedure was carried out in sterile tubes containing $5 \mathrm{ml}$ of culture medium ( $99 \%$ RPMI 1640 and $1 \%$ Penicillin-Streptomycin, without serum in order to prevent protein interaction). All samples were kept in this medium at $37{ }^{\circ} \mathrm{C}$ for 30 minutes and it was observed that they were completely dissolved during this time period. Equal sample of an aluminum foil was also used simultaneously in the experiments as a reference base support material of NFs and treated as a sample and also extraction medium without sample was used as control and culture medium containing $1 \%$ Triton X-100 was used as a positive control.

\section{Cell culture}

All experimental parts of cell culture and cytotoxicity assays were conducted at the cell culture laboratory of Bioengieering Department of Bursa Technical University according to the good cell culture practices Coecke et al. (2005) [32]. The L929 cell lines (mouse fibroblasts) were used for cytotoxicity assays as a reference cell line for cytotoxicity testing of medical devices and materials, according to the UNI EN ISO 10993-5rule:2009 [33]. L929 cells (kindly obtained from Yeditepe University, Department of Genetics and Bioengineering) were seeded in $75 \mathrm{~cm}^{2}$ culture flasks containing RPMI 1640 supplemented with $10 \%$ FBS and $1 \%$ penicillin streptomycin. Cells were grown in an incubator at $37^{\circ} \mathrm{C}$ in an atmosphere supplemented with $5 \% \mathrm{CO}_{2}$ and monitored daily by using an inverted microscope with phase contrast attachment (Olympus CKX41). Subcultures were performed when an $80 \%$ of confluence was observed. Following disaggregation with trypsin/EDTA and resuspension of cells in medium, a total of $5 \times 10^{4}$ cells/well were plated in 96 well tissue-culture plates.

\section{Determination of the cytotoxicity of nanofibers by 3-(4,5-Dimethylthiazol-2-yl)-2,5-diphenyltetrazolium bromide (MTT) assay}

MTT assay was performed by the method of Mosmann (1983) [34] with the modifications of Hansen et al. (1989) [35] and Kuz'ma et al. (2012) [36]. After $24 \mathrm{~h}$ incubation of cells seeded in 96 well tissue-culture plates, cells were exposed to the different concentrations of nanofiber extract solutions in medium for 24 $\mathrm{h}$ at $37^{\circ} \mathrm{C}$ in $5 \% \mathrm{CO} 2$ in air. After exposure, the medium was aspirated and MTT $(5 \mathrm{mg} / \mathrm{ml}$ of stock in PBS) was added (10 $\mu \mathrm{l} /$ well in $100 \mu \mathrm{l}$ of cell suspension), and cells were incubated for an additional $4 \mathrm{~h}$ 
with MTT dye. At the end of incubation period, the dye was carefully taken out and $100 \mu$ of DMSO was added to each well. The absorbance of the solution in each well was measured in a microplate reader at $570 \mathrm{~nm}$. Results were expressed as the mean percentage of cell growth from three independent experiments.

\section{Determination of the cytotoxicity of nanofibers by neutral red uptake (NRU) assay}

The cytotoxicity of nanofibers was performed in L929 cells by NRU assay following the protocols described by Virgilio et al. (2004) [37] and Saquib et al. (2012) [38]. After $24 \mathrm{~h}$ incubation of L929 cells in 96 well plates, $200 \mu \mathrm{l}$ of all sample solutions were added. The cells were incubated for $24 \mathrm{~h}$ at $37^{\circ} \mathrm{C}$ in $5 \%$ $\mathrm{CO} 2$ in air, then the medium was aspirated. The cells were washed twice with PBS and incubated for an additional $3 \mathrm{~h}$ in the medium supplemented with $\mathrm{NR}(50 \mu \mathrm{g} / \mathrm{ml})$. After the medium was discarded, the cells were rinsed five times with warm PBS ( $\mathrm{pH} 7.4)$ to remove the non incorporated excess dye and 200 $\mu \mathrm{l}$ of destain solution ( $50 \%$ ethanol, $1 \%$ acetic acid, and $49 \%$ distilled water) was added to each well to fix the cells and bring the NR into solution. The plates were shaken for $20 \mathrm{~min}$, and the absorbance of the solution in each well was measured in a microplate reader at $540 \mathrm{~nm}$ and compared with wells containing untreated cells. Results were expressed as the mean percentage of cell growth from three independent experiments.

\section{Results And Discussion}

\subsection{Morphology of electrospun nanofibers}

The morphology of the resulting electrospun fibers was investigated with SEM and presented in Fig. 3, respectively. When comparing with SEM images of PVA and PVA/FA fibers, neat PVA sample has intensive beads on a string structure in the fiber (Fig. 3A\&B). However, applying to electrospray procedure of FA on the fibers enhanced the formation of beadless morphology. With the adding of FA, the average diameter of fiber with beads decreased from about $532 \mathrm{~nm}$ (neat PVA) to about 291 nm (PVA/FA) (Fig. 43A\&B). Folic acid molecules connected PVA fibers showed a little rough, randomly interconnected structure with FA clusters formed. Unfortunately, folic acid clusters were not seen too much on surface of the PVA fibers and this situation can be explained by using the same solvent in both electrohydrodynamic process and thus folic acid molecules attached into PVA fibers. The addition of gelatin into PVA solution also provided thin and homogenous fiber structure (Fig. 3C). PVA/Gel fibers with thin and regular structure were also obtained previously by Lihn et al. [39]. Furthermore, PVA-Gel NFs had a predominant fiber diameter of 80-120 nm; whereas, PVA-Gel/FA fibers had a fairly even distribution ranging from 60 to $220 \mathrm{~nm}$. (Fig. 4 C\&D). Folic acid molecules caused to form of thicker fiber structure and destroyed the homogenous fiber morphology. There were $2 \mathrm{D}$ flat fiber forms in some regions. In addition, folic acid clusters on the gelatin fibers were seen clearly. Fig. 3E displays the blend of PVA and alginate fibers. The diameter of fiber increases by adding alginate into PVA solution. Therefore the resulting blend sample has shown slightly interconnected fiber morphology. Although there are FA beads on the PVA-alginate fibers, the structure destroyed seriously during electrospraying of FA. The reason of this is similar to 
PVA/FA fibers related to same solvent for two hydrodynamic process. As shown in Fig. 4E and F, nanoscale PVA-Alg and PVA-Alg/FA fibers were produced with diameters ranging from 150 to $550 \mathrm{~nm}$ and 50 to $350 \mathrm{~nm}$, respectively.

As a result, SEM images revealed FA clusters have both partially deposited on the surfaces of hydrophilic fibers and integrated into the fiber structure. Moreover, morphology PVA fibers with beads enhanced with their blends.

\subsection{Thermal Properties}

Fig. 5 illustrates TGA and DTG thermograms for neat PVA, PVA blends and FA loaded electrospun PVA fibers. All electrospun fibers show weight loss in the range of $30-100^{\circ} \mathrm{C}$ related to moisture out of fibers. The amount of weight loss was different for all fibers. The maximum weight loss was seen at the PVAGel/FA mixture and the minimum was at the PVA/FA mixture. The amount of the weight losses were 9.28 $\%$ and $4.15 \%$ for PVA-Gel/FA and PVA/FA , respectively. Apart from the weight loss related to moisture out three steps of weight loss were observed for the neat PVA fiber. The major weight losses of $43 \%$ taken place in the temperature range from $210^{\circ} \mathrm{C}$ to $350^{\circ} \mathrm{C}$ due to dehydration of PVA $[40,41]$. The second step is dominated by chain scission about $450^{\circ} \mathrm{C}$ to $600^{\circ} \mathrm{C}$ [42] and the amount of weight loss was $8.18 \%$. The last step was related to burning of the pyrolysis product which was formed during analysis in the $\mathrm{N}_{2}$ atmosphere. The weight loss of $3.77 \%$ from the last step. It is found that FA loaded PVA fibers started to decompose at about $150^{\circ} \mathrm{C}$ with $45 \%$ weight loss and continue to $300^{\circ} \mathrm{C}$. The following weight loss of $13 \%$ from $350^{\circ} \mathrm{C}$ to $460^{\circ} \mathrm{C}$ was attributed to both elimination reaction of PVA and loss of pterin and then p-aminobenzoic acid units in folic acid. The last step was related to burning of the pyrolysis product which was formed during analysis in the $\mathrm{N}_{2}$ atmosphere. The amount of weight loss was $8.83 \%$ in this step.

The first weight loss of almost $67 \%$ apart from moisture out was seen between $280-450^{\circ} \mathrm{C}$ for PVA-Gel fibers. The second weight loss in the amount of $6.49 \%$ was occurred in the region of $450-550{ }^{\circ} \mathrm{C}$. The last weight loss was about $11.68 \%$ related to pyrolysis product which was formed during analysis in the $\mathrm{N}_{2}$ atmosphere. The weight loss of blend fiber had a decrease at $280^{\circ} \mathrm{C}$ and continue to $500^{\circ} \mathrm{C}$ with $78 \%$ weight loss which was mainly due to the cleavage of $\mathrm{C}=\mathrm{N}$ bond is concerned with the presence of protein molecules in gelatin [43].

Thermal behavior of the PVA-Gel/FA was slightly difference from the thermogram of the PVA-Gel. The difference was only at the region of the $150-250^{\circ} \mathrm{C}$ temperature. There was slightly weight loss of the PVA-Gel/FA (about $3.34 \%$ ). The other difference was occurred after the temperature of the $450^{\circ} \mathrm{C}$ due to the FA content. The decomposition speed was decrease as a consequence of $\mathrm{C}=\mathrm{N}$ group.

The lowest decomposition temperature was occurred for PVA/Alg blend nanofibers about $170^{\circ} \mathrm{C}$ [44]. The first decomposition weight loss of $68 \%$ from the fiber is related to dehydration of PVA. The second decomposition step temperature range of about $350-450^{\circ} \mathrm{C}$, corresponding to the degradation of alginate with weight loss of 7.52 . The third decomposition step the temperature ranges of about $450-600^{\circ} \mathrm{C}$ with 
weight loss of $6.21 \%$ from the fiber was related to PVA chain scission as the other PVA samples. The loss of the moisture from PVA-Alg/FA was less than the PVA-Alg. Furthermore, as seen in Fig. 5, PVA-Alg fibers showed faster decomposition than PVA-Alg/FA after $450^{\circ} \mathrm{C}$. There is no residue for all NFs.

\subsection{FT-IR Analysis}

The chemical composition of the all electrospun fibers and folic acid were determined through FT-IR analysis. As seen in Fig. 6, the spectrum of folic acid has a number of characteristic peaks at 3590, 3496, $3330,2925,2840,1694,1650,1605,1487$ and $1405 \mathrm{~cm}^{-1}$. The band between $3600-3300 \mathrm{~cm}^{-1}$ is associated with $(-\mathrm{OH})$ stretching bands of glutamic acid moiety and $-\mathrm{NH}$ group of pterin ring. The band at $1650 \mathrm{~cm}^{-1}$ belongs to the $(-\mathrm{C}=0)$ stretching of $\left(-\mathrm{CONH}_{2}\right)$. The another characteristic IR absorption peaks at 1605,1694 and $1487 \mathrm{~cm}^{-1}$ is due to the $\mathrm{N}-\mathrm{H}$ bending vibration of $(-\mathrm{CONH})$ group, $(-\mathrm{C}=0)$ amide stretching of the a-carboxyl group and absorption band of phenyl ring respectively [45-47]. The frequencies for the neat PVA are indicated as follows: $3284 \mathrm{~cm}^{-1}$ for the stretching vibration peak of its (-OH) groups, 2943 and $2910 \mathrm{~cm}^{-1}$ for the stretching vibration of $-\mathrm{CH}_{2}$ group, 1242, 1088, 1023 and $945 \mathrm{~cm}^{-1}$ (C-0) stretching vibration, respectively $[41,48,49]$. On the other hand, for the PVA-Gel fibers the band appears at $3290 \mathrm{~cm}^{-1}$ for the (-OH) group. The bands appear at 2938 and $2913 \mathrm{~cm}^{-1}$ belongs to $-\mathrm{CH}_{2}$ stretching vibration. The characteristic absorption of gelatin peaks show mainly to the peptide bonds (-CONH) with the amide I-III vibrations. The peak is $1643 \mathrm{~cm}^{-1}$ (amide-l) is related to $-\mathrm{C}=0$ stretching vibration whereas the peak at $1535 \mathrm{~cm}^{-1}$ (amide-II) is due to $\mathrm{N}-\mathrm{H}$ bending and $\mathrm{C}-\mathrm{H}$ stretching vibration. $1243 \mathrm{~cm}^{-1}$ for the (amide-III) peak was occurred. In addition, $1435 \mathrm{~cm}^{-1}$ (- $\mathrm{CH}_{2}$ bending), $1374 \mathrm{~cm}^{-1}$ (C-H wagging), $1088 \mathrm{~cm}^{-1}$ (-C-O-C) and $837 \mathrm{~cm}^{-1}(\mathrm{C}-\mathrm{C})$ stretching $[50,51]$.

In literature, the characteristic peaks of alginate assigned $3297 \mathrm{~cm}^{-1}$ (-OH stretching), $2940 \mathrm{~cm}^{-1}\left(-\mathrm{CH}_{2}\right.$ stretching), 1612 and $1424 \mathrm{~cm}^{-1}$ asymmetric and symmetric (-COO) stretching and also $1096 \mathrm{~cm}^{-1}$ (C-O) stretching vibrations, respectively [52]. The electrospun PVA-Alg and PVA fibers were same absorption peaks approximately. However, the absorption peaks at $3284 \mathrm{~cm}^{-1}$ (-OH stretching) belongs to PVA that shifted to the $3297 \mathrm{~cm}^{-1}[53,54]$.

It is worth mentioning that the spectrums of NFs with drug (Fig. 6) were similar the spectrum to neat NFs, indicating the absence of any chemical reaction between polymer and drug. This is explained by $-\mathrm{OH}$ groups in polymer structures shielded the characteristic peaks of drug molecules between $3300-3600 \mathrm{~cm}^{-}$

1 , corresponding to penetration of drug into the fibers. Additionally, the characteristic peaks of drug molecules could not seen after $1700 \mathrm{~cm}^{-1}$ due to the low intensity.

\subsection{UV-Vis Spectroscopy- in vitro Study}

UV-Vis spectrometry was used to evaluate the release profile of FA from the nanofibers, which helped to reveal the structure-function relationship of the electrospun FA-loaded fibers in artificial sweat solution 
$\left(\mathrm{pH} 5.44,37^{\circ} \mathrm{C}\right)$ during the time course of $480 \mathrm{~min}$. The cumulative FA release rate profiles, in the sweat solution FA from the fiber samples, are plotted in Fig. 7.

The release profile shows that the percentage cumulative FA releases are $49.6 \%, 69.55 \%$ and $50.88 \%$ for PVA/FA, PVA-Gel/FA and PVA-Alg/FA, respectively after 8 h. As seen in Fig. 7, all fibers exhibited initial burst release profile at an early stage of the analysis. Especially, in PVA/FA fiber at an early stage of the analysis within first $5 \mathrm{~min}$, more than half of the FA was released from the fiber. In PVA-Gel/FA fiber within first 30 min about $65 \%$ FA release whereas in PVA-Alg/FA composite fibers $49 \%$ FA release. The rapid release of FA from the composite fibers is related to many factors, such as hydrophilic nature of matrix (PVA, gel and alg), high surface area of fibers that supports to increase in wettability $[55,56]$. Illangakoon et al. have reported hydrophilic PVP with paracetamol/caffeine NFs release almost all caffein and paracetamol within the first 6 min [57]. In this study, the burst release behavior of all fibers might be related to the existence of hydrophilic based polymer matrix and drug as well. Furthermore, drug molecules depositted on the fiber surface also cause the initial release due to the hybrid process. On the other hand, burst release is a phenomenon which may be preferred to obtain quick results in dermal applications [58]. Kataria et al. also prepared ciprofloxacin loaded transdermal patches with fast release. In this study, the resulting PVA and PVA-Alg with ciprofloxacin fibers have sustained and controlled release profile and reached maximum drug release curve in the first 7 hours [20].

It is clearly seen PVA-Gel/FA had the slowest behavior in fibers for $30 \mathrm{~min}$. From the SEM images, the average fiber diameter of PVA/FA, PVA-Gel/FA and PVA-Alg/FA are 291, 145 and $158 \mathrm{~nm}$. Moreover, the sample has the highest drug release rate compared with the other samples in total time. This is explained as the thickness of the fibers increase, the pathway drug diffusion of will increase [59].

The maximum drug was released from the fibers within sustained behaviour untill $45 \mathrm{~min}$. From the Fig. 7 showed diffusion based drug release occured for $30 \mathrm{~min}$, then followed by a constant drug release till $8 \mathrm{~h}$ due to erosion of polymer matrix. Similar UV-Vis results were reported by Arthani et al. [53]. However, the release rate in PVA-Gel/FA fiber is partially slower than others for the first $30 \mathrm{~min}$. due to the interaction hydrogen bonding between PVA, gelatin and folic acid. PVA-Alg/FA fiber also indicated similar situation, but unfortunately the low amount of alginate in the fiber limit the formation of too many interaction of hydrogen bonding (Fig. 6). Consequently, PVA-Gel/FA could be used as an efficient drug delivery system for beauty mask purpose with $8 \mathrm{~h}$ period.

Recently, there have been a variety approaches about COVID-19 pandemia. In this regard, inhibition of furin enzyme activity provide to limit of viral and bacterial growth [60]. Sheybani et al. have claimed that folic acid prevents furin activation. It has been simulated folid acid could be a potential drug in early respiratory diseases caused by COVID-19 [61]. Results of the study indicates folic acid molecules interacted with active sites of furin due to formation of hydrogen bonds. Therefore, we also proposed nanofiber with folic acid as a patch may prevent the COVID-19.

\subsection{Cytotoxic effects of nanofibers by MTT assay}


The cytotoxic effects of PVA/FA, PVA-Gel/FA and PVA-Alg/FA nanofibers extract solutions were evaluated by MTT assay in L929 cells. To determine and compare the cytotoxicity, extract solutions of all NFs and alsoa negative control group without any chemicals, aluminum foil as a planch material and a positive control group containing $1 \%$ Triton $\mathrm{x}-100$ were prepared. Eight wells of each sample were repeated in 96 well plates. The average absorbance values and standard deviation values of living cells were calculated by averaging all the data obtained. In addition, cell viability in the control group was considered as $100 \%$, and living cell percentages were determined for all samples compared to the control. Results of MTT test are shown in Fig. 8. According to the results of MTT test applied after 24 h o treatment in L929 cells, the groups treated with nanofiber extracts caused some decreases in cell viability in all groups compared to the negative control group. However, since viability did not fall below $70 \%$, it was not evaluated as cytotoxic by MTT assay.

\subsection{Cytotoxic effects of nanofibers by NRU assay}

The cytotoxic effect of the extract solutions of prepared NFs were evaluated by NRU assay in L929 cells. Results of NRU test are shown in Fig. 9. According to the results of NRU test applied after $24 \mathrm{~h}$ of treatment in L929 cells, the groups treated with nanofiber extracts caused decreases in cell viability in all

groups compared to the negative control group. Except the PVA-Gel NF cell viability decreased under $70 \%$, but not decreased under 50\%. PVA-Alg NFs caused more cytotoxicity in NRU assay. On the other hand, L929 cells were treated with a high concentrations of nanofiber extracts in this study to investigate exact cytotoxicity.

In the NRU method, which is based on the measurement principle of lysosomal activity, cell viability is shown by a different mechanism than MTT assay (based on the measurement of mitochondrial activity as metabolic activity). It is thought that the nanofiber extract solutions may cause toxic effects by interacting with the cell membrane or enter the cell through the membrane and accumulating in organelles and cytoplasm.

\section{Conclusions}

In this study, we successfully produced fast-dissolving drug delivery systems derived from hydrophilic composite fibers by simultaneous electrospraying and electrospinning method. FA was used as model drug and the resulting composite fibers consists of FA clusters entrapped in PVA, PVA-Gel and PVA-Alg NFs. The SEM images showed the composite fibers possessed relatively uniform with average fiber diameters between 145-291 nm and most of the FA clusters have been integrated into the fibers rather than deposit on the fiber surface due to polymers and folic acid solutions are hydrophilic based nature. Moreover, as FA is added fiber morphology is formed with bead-free for PVA/FA fiber. The FTIR spectra results demonstrated the apparent slight shifts of some peaks, corresponding to physical interactions of FA with fibers. The TGA results pointed out that by the incorporation of FA into NFs, the degradation rate was increased slightly. However, FA was stable at high temperature. The in vitro release test clearly confirmed that the obtained PVA/FA, PVA-Gel/FA and PVA-Alg/FA NFs could release the FA in a sustained 
manner with initial burst release for the 8 hour-period. The observation of fast dissolving of all fibrous structures with FA in 30 min is directly related to two reasons : the strong hydrophilic nature of PVA, PVAGel and PVA-Alg NFs and FA clusters deposited on fiber surfaces due to electrospraying process.

The biocompatibility test results based on the cytoxicity methods adapted from the IS010993-5 standards indicatednovel PVA/FA, PVA-Gel/FA and PVA-Alg/FA electrospun nanofibrous patches revealed no cell toxicity on cultured fibroblasts in MTT assay but slight cell toxicity in NRU assay. In this study L929 cells were treated with a high concentrations of nanofiber extracts to investigate exact cytotoxicity due to the nature of certain biodegradable/ leachable and extractable biomaterials. As indicated in biocompatibility test protocols the quantity exposed to used cell lines is dependent to the interface area, the volume of extraction, $\mathrm{pH}$, temperature, time and many other factors. Results of this study and similar studies in the literature also indicated that the cytotoxic effect the different PVA nanofibers are based on the components and content amounts. Our results reveal that PVA and PVA-Gel with/without FA nanofibers seems more biocompatible than PVA-Alg nanofibers. However, further biocompatibility tests should be carried out in different conditions, concentrations and different cell lines according to potential use for dermal or other biomedical applications as scaffolds. Moreover, the new nanofibers can also be used as an effective patch against the COVID-19 thanks to folic acid molecules.

\section{Declarations}

\section{Acknowledgements}

This study was supported by Bursa Technical University Scientific Research Projects Coordination Unit (SRP Project No. 190D003). The authors of this study would like to express their appreciations to Murat EROĞLU and Ibrahim ŞEN (Central Research Laboratory, Bursa Technical University) for his help in SEM and TGA analysis and employees of Scientific and Technological Research Council of Turkey-Bursa Test and Analysis Laboratory (TUBITAK-BUTAL) for supporting the preparation of artificial sweat solutions.

\section{Conflict of interest}

The authors declare no conflict of interest.

\section{References}

[1] Kamble P, Sadarani B, Majumdar A, Bhullar S (2017) Nanofiber based drug delivery systems for skin: A promising therapeutic approach. J. Drug Deliv Sci Tec 4:124-133.

[2] Geerligs M (2009) Skin layer mechanism. Eindhoven, The Netherlands pp 4-5.

[3] Rodrigues F et al (2018) Polyphenols: Properties, Recovery, and Applications, Cosmetics. Elsevier pp 393-427. 
[4] Sheshala R, Anuar NK, Samah NHA, Wong TW (2019) In Vitro Drug Dissolution/Permeation Testing of Nanocarriers for Skin Application: a Comprehensive Review. AAPS Pharm Sci Tech 20:1-28.

[5] Mancini AJ, Krowchuk DP (2016) Pediatric Dermatology, 3rd Edition, American Academy of Pediatrics pp 1-2.

[6] Parikh SA, Kelsey A, Finch J, Grant-Kels JM (2019) Healthy Aging, Skin Health and Healthy Aging: Skin Cosmetics pp 105-113.

[7] Scheuplein RJ, Blank IH (1971) Permeability of the Skin. Physiol Rev 51:4.

[8] Flynn GL, Yalkowsky SH, Roseman TJ (1974) Mass transport phenomena and models: Theoretical concepts. J Pharm Sci 63:479-510.

[9] Ranade VV (1991) Drug Delivery Systems Transdermal Drug Delivery. J Clin Pharmacol 31:401-418.

[10] Goyal R, Macri LK, Kaplan HM, Kohn J (2016) Nanoparticles and nanofibers for topical drug delivery. J Control Release 240:77-92.

[11] Banga AK (2011) Transdermal and intradermal delivery of therapeutic agents: Application of physical technologies. Drug Dev Ind Pharm 38:513.

[12] Murthy SN (2012) Transdermal drug delivery: approaches and significance. Res and Rep Trans Drug Deliv 1:1-2.

[13] Petrilli R, Lopez RFV (2018) Physical methods for topical skin drug delivery: concepts and applications. Braz J Pharm Sci 54:1-19.

[14] Bos JD, Meinardi MM (2000) The 500 Dalton rule for the skin penetration of chemical compounds and drugs. Exp Dermatol 9:165-169.

[15] Esentürk I, Erdal MS, Güngör S (2016) Electrospinning method to produce drug-loaded nanofibers for topical/ transdermal drug delivery applications. J Fac Pharm 46:49-69.

[16] Galkina OL, Ivanov VK, Agafonov AV, Seisenbaeva GA, Kessler VG (2015) Cellulose nanofibers titania nanocomposites as potential drug delivery systems for dermal applications. J Mater Chem B 3:1688-1698.

[17] Gencturk A, Kahraman E, Güngör S, Özhan G, Özsoy Y, Sarac AS (2017) Polyurethane/hydroxypropyl cellulose electrospun nanofiber mats as potential transdermal drug delivery system: characterization studies and in vitro assays. Artif Cell Nanomed B 45:655-664.

[18] Esentürk I, Balkan T, Özhan G, Döşler S, Güngör S, Erdal MS, Sarac AS (2020) Voriconazole incorporated nanofiber formulations for topical application: preparation, characterization and antifungal activity studies against Candida species. Pharm Dev Tech 25:440-453. 
[19] Shen X, Xu Q, Xu S, Li J, Zhang N, Zhang L (2014) Preparation and Transdermal Diffusion Evaluation of the Prazosin Hydrochloride-Loaded Electrospun Poly(vinyl alcohol) Fiber Mats. J Nanosci Nanotechnol 14:5258-5265.

[20] Kataria K, Gupta A, Rath G, Mathur RB, Dhakate SR (2014) In vivo wound healing performance of drug loaded electrospun composite nanofibers transdermal patch. Int J Pharm 20:102-10.

[21] Tran T, Hernandez M, Patel D, Burns E, Peterman V, Wu J (2015) Controllable and switchable drug delivery of ibuprofen from temperature responsive composite nanofibers. Nano Converg 2:1-7.

[22] Song J, Fan X, Shen Q (2016) Daidzein-loaded nanostructured lipid carriers-PLGA nanofibers for transdermal delivery. Int J Pharm 501:245-252.

[23] Madhaiyan K, Sridhar R, Sundarrajan S, Venugopal JR, Ramakrishna S (2013) Vitamin B12 loaded polycaprolactone nanofibers: A novel transdermal route for the water soluble energy supplement delivery. Int J Pharm 444:70-76.

[24] Sheng X, Fan L, He C, Zhang K, Mo X, Wang H (2013) Vitamin E-loaded silk fibroin nanofibrous mats fabricated by green process for skin care application. Int J Biol Macromol 56:49-56.

[25] Li H, Wang M, Williams GR, Wu J, Sun X, Lv Y, Zhu LM (2016) Electrospun gelatin nanofibers loaded with vitamins A and $E$ as antibacterial wound dressing materials. RSC Adv 6: 50267-50277.

[26] He L, Zhao Y, Tian L, Ramakrishna S (2018) Electrospraying and Electrospinning for Nanobiomaterial Fabrication Nanobiomaterials: Classification, Fabrication and Biomedical Applications. First Edition Wiley, pp 143-163.

[27] Sridhar R, Ramakrishna S (2013) Electrosprayed nanoparticles for drug delivery and pharmaceutical applications. Biomatter 3:24281.

[28] Schmid-Wendtner MH, Korting HC (2006) The pH of the Skin Surface and Its Impact on the Barrier Function Skin Pharmacol Physiol 19:296-302.

[29] Gazzali AM et al (2016) Stability of folic acid under several parameters. Eur J Pharm Sci 93:419-430.

[30] International Organization for Standardization, ISO 105-E04:2013, "Textiles - Tests for colour fastness - Part E04: Colour fastness to perspiration", International Organization for Standardization, Geneva, Switzerland.

[31] International Organization for Standardization, UNI EN ISO 10993-5:2009, "Biological Evaluation of Medical Devices-Part 5: In Vitro Cytotoxicity Testing", International Organization for Standardization, Geneva, Switzerland. 
[32] Coecke S (2005) Guidance On Good Cell Culture Practice, A Report Of The Second Ecvam Task Force On Good Cell Culture Practice. Altern Lab Anim 33:261-287.

[33] International Organization for Standardization, UNI EN ISO 10993-12:2009, "Biological Evaluation of Medical Devices-Part 12: Preparation of Samples and Reference Materials", International Organization for Standardization, Geneva, Switzerland.

[34] Mosmann T (1983) Rapid colorimetric assay for cellular growth and survival: application to proliferation and cytotoxicity assays. J Immunol Methods 65:55-63.

[35] Hansen MB, Nielsen SE, Berg K (1989) Re-examination and further development of a precise and rapid dye method for measuring cell growth/cell kill. J Immunol Methods 119:203-210.

[36] Kuźma Ł, Wysokińska H, Różalski M, Krajewska U, Kisiel W (2012) An unusual taxodione derivative from hairy roots of Salvia austriaca. Fitoterapia 83:770-773.

[37] Virgilio LD, Iwami K, Wätjen W, Kahl R, Degen GH (2004) Genotoxicity of the isoflavones genistein, daidzein and equol in V79 cells. Toxicol Lett 151:151-162.

[38] Saquib Q, Al-Khedhairy AA, Siddiqui MA, Abou-Tarboush FM, Azam A, Musarrat J (2012) Titanium dioxide nanoparticles induced cytotoxicity, oxidative stress and DNA damage in human amnion epithelial (WISH) cells. Toxicol in Vitro 26:351-361.

[39] Linh NTB, Min YK, Song HY, Lee BT (2010) Fabrication of polyvinyl alcohol/gelatin nanofiber composites and evaluation of their material properties. J Biomed Mater Res B, 95:184-191.

[40] Rianjanu A, Kusumaatmaja A, Suyono EA, Triyana K (2018) Solvent vapor treatment improves mechanical strength of electrospun polyvinyl alcohol nanofibers. Heliyon 4:1-19 .

[41] Lee JH, Lee US, Jeong K, Seo Y, Park S, Kim H (2010) Preparation and Characterization of Polyvinyl alcohol nanofiber mats crosslinked with blocked isocyanate prepolymer. Polym Int 59:1683-1689.

[42] Taepaiboon P, Rungsardthong U, Supaphol P (2006) Drug-loaded electrospun mats of poly(vinyl alcohol) fibres and their release characteristics of four model drugs. Nanotechnol 17:2317-2329.

[43] Karmaker N, Islam F, Islam N, Razzak M, Koly FA, Chowdhury AMS, Khan RA (2019) Fabrication and Characterization of PVA-Gelatin-Nano Crystalline Cellulose based Biodegradable Film: Effect of Gamma Radiation. J Res Updates Polym Sci 8:7-14.

[44] Islam S, Karim MR (2010) Fabrication and characterization of poly(vinyl alcohol)/alginate blend nanofibers by electrospinning method. Colloids Surf A: Physicochem Eng Asp 366:135-140.

[45] Varshosaz J, Hassanzadeh F, Sadeghi Aliabadi H, Nayebsadrian M, Banitalebi M, Rostam M (2014) Synthesis and Characterization of Folate-Targeted Dextran/Retinoic Acid Micelles for Doxorubicin 
Delivery in Acute Leukemia. BioMed Res Int 2014:1-14.

[46] Yadav V, Rohilla Y, Choudhary M, Choudhary N, Budhwar V (2018) Physicochemical, pharmacological and analytical profile of folic acid: a comprehensive review. Int Res J Pharm 9:6-15.

[47] İnce İ, Yıldırım Y, Güler G, Medine El, Ballıca G, Kuşdemir BC, Göker E (2020) Synthesis and characterization of folic acid-chitosan nanoparticles loaded with thymoquinone to target ovarian cancer cells. J Radioanal Nucl 324:71-85.

[48] Kuo TY, Jhang CF, Lin CM, Hsien TY, Hsieh HJ (2017) Fabrication and application of coaxial polyvinyl alcohol/chitosan nanofiber membranes. Open Phys 15:1004-1014.

[49] Sekar AD, Muthukumar H, Chandrasekaran NI, Matheswaran M (2018) Photocatalytic degradation of naphthalene using calcined FeZnO/ PVA nanofibers. Chemosphere 205:610-617.

[50] Huang CY, Hu KH, Wei ZH (2016) Comparison of cell behavior on pva/pva-gelatin electrospun nanofibers with random and aligned configuation. Sci Rep 6:1-8.

[51] Yang C, Wu X, Zhao Y, Xu L, Wei S (2011) Nanofibrous Scaffold Prepared by Electrospinning of Poly(vinyl alcohol)/Gelatin Aqueous Solutions. J Appl Polym Sci 121:3047-3055.

[52] Tamizi E, Azizi M, Dorraji MSS, Dusti Z, Panahi-Azar V (2017) Stabilized core/shell PVA/SA nanofibers as an efficient drug delivery system for dexpanthenol. Polym Bull 75:547-560.

[53] Arthanari S et al (2016) Preparation and characterization of gatifloxacin-loaded alginate/poly (vinyl alcohol) electrospun nanofibers. Artif Cell Nanomed B 44(3):847-852.

[54] Aadil KR, Nathani A, Sharma CS, Lenka N, Gupta, P (2018) Fabrication of biocompatible alginatepoly(vinyl alcohol) nanofibers scaffolds for tissue engineering applications. Mater Technol 33:507-512.

[55] Vuddanda PR, Mathew AP, Velag S (2016) Electrospun nanofiber Mats for ultrafast release of ondansetro. React Func Polym 55:65-72.

[56] Aavani F, Khorshidi S, Karkhaneh AA (2019) concise review on drug-loaded electrospun nanofibres as promising wound dressings. J Med Eng Technol 43:38-47.

[57] Illangakoon UE, Gill H, Shearman GC, Parhizkar M, Mahalingam S, Chatterton NP, Williams GR (2014) Fast dissolving paracetamol/caffeine nanofibers prepared by electrospinning. Int J Pharm 477:369-379.

[58] Iqbal H, Khan ZU, Razzaq A, Khan NU, Menaa B, Khan BA, Menaa F (2019) Fabrication, Physical Characterizations and In Vitro Antibacterial Activity of Cefadroxil-Loaded Chitosan/Poly(Vinyl Alcohol) Nanofibers against Staphylococcus aureus Clinical Isolates. Int J Biol Macromol 1:921-931.

[59] Akduman C, Özgüney I, Akcakoca Kumbasar EP (2016) Preparation and characterization of naproxen-loaded electrospun thermoplastic polyurethane nanofibers as a drug delivery system. Mater Sci 
Eng C 64:383-390.

[60] Coutard B, Valle C, Lamballerie X, Canard B, Seidah NG, Decroly E (2020) The spike glycoprotein of the new coronavirus 2019-nCoV contains a furin-like cleavage site absent in CoV of the same clade. Antivir Res doi: 10.1016/j.antiviral.2020.104742.

[61] Sheybani Z et al (2020) The role of folic acid in the management of respiratory disease caused by COVID-19. ChemRxiv doi: 10.26434/chemrxiv.12034980.

\section{Figures}

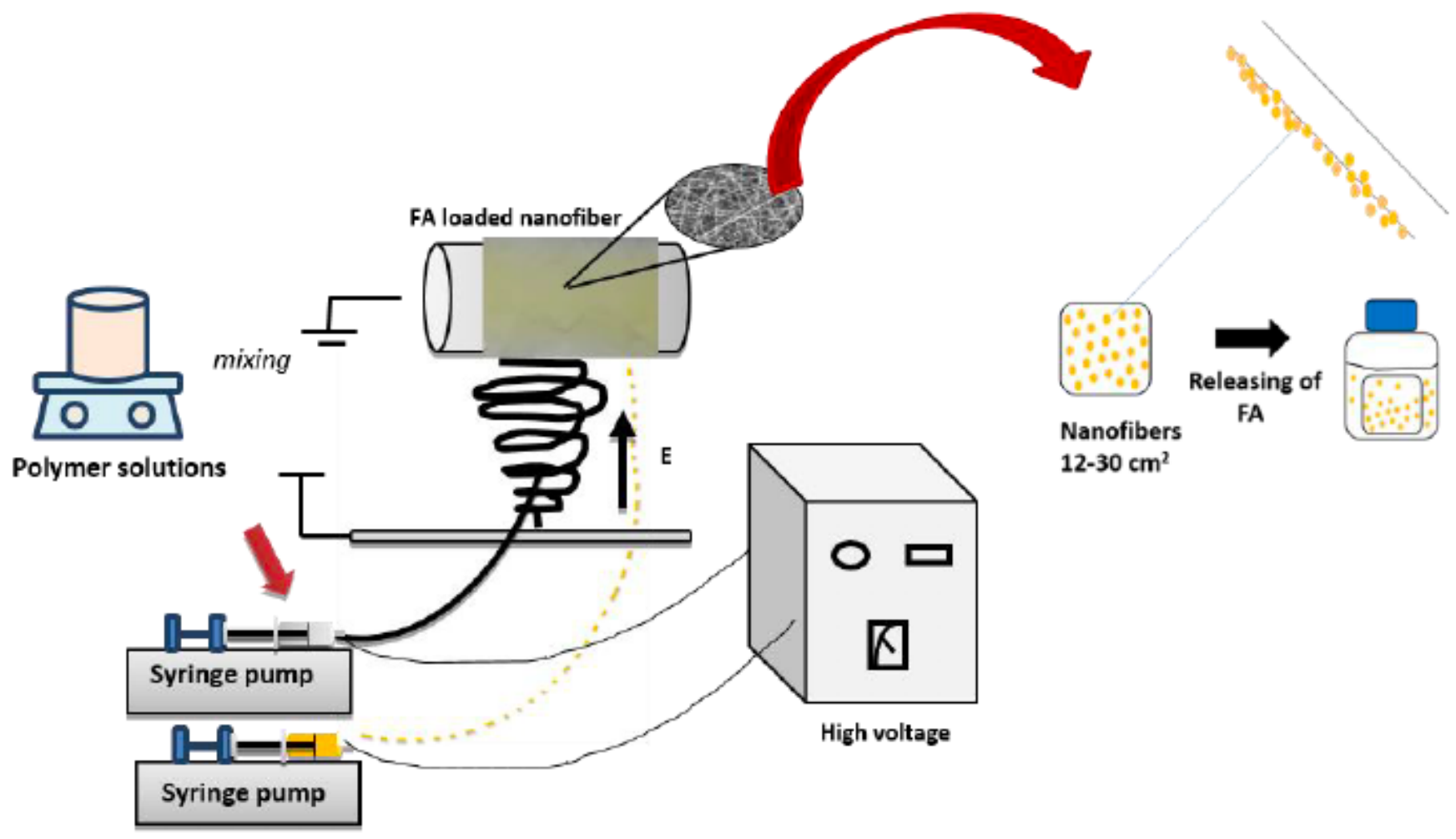

Figure 1

Schematic illustration of hybrid process of nanofibers. 


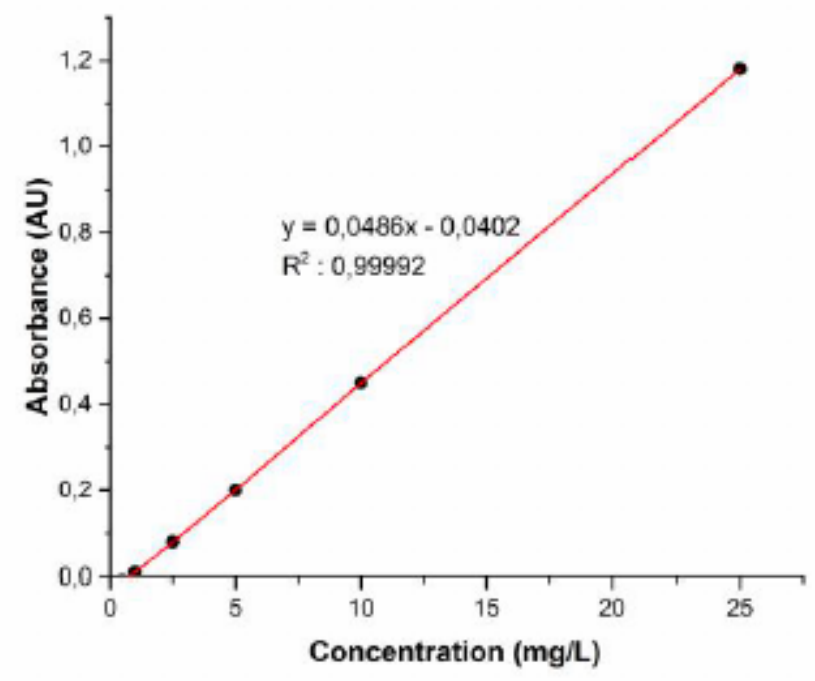

Figure 2

Calibration curve of FA at maximum $282 \mathrm{~nm}$ in acidic sweat solution pH 5.44. 

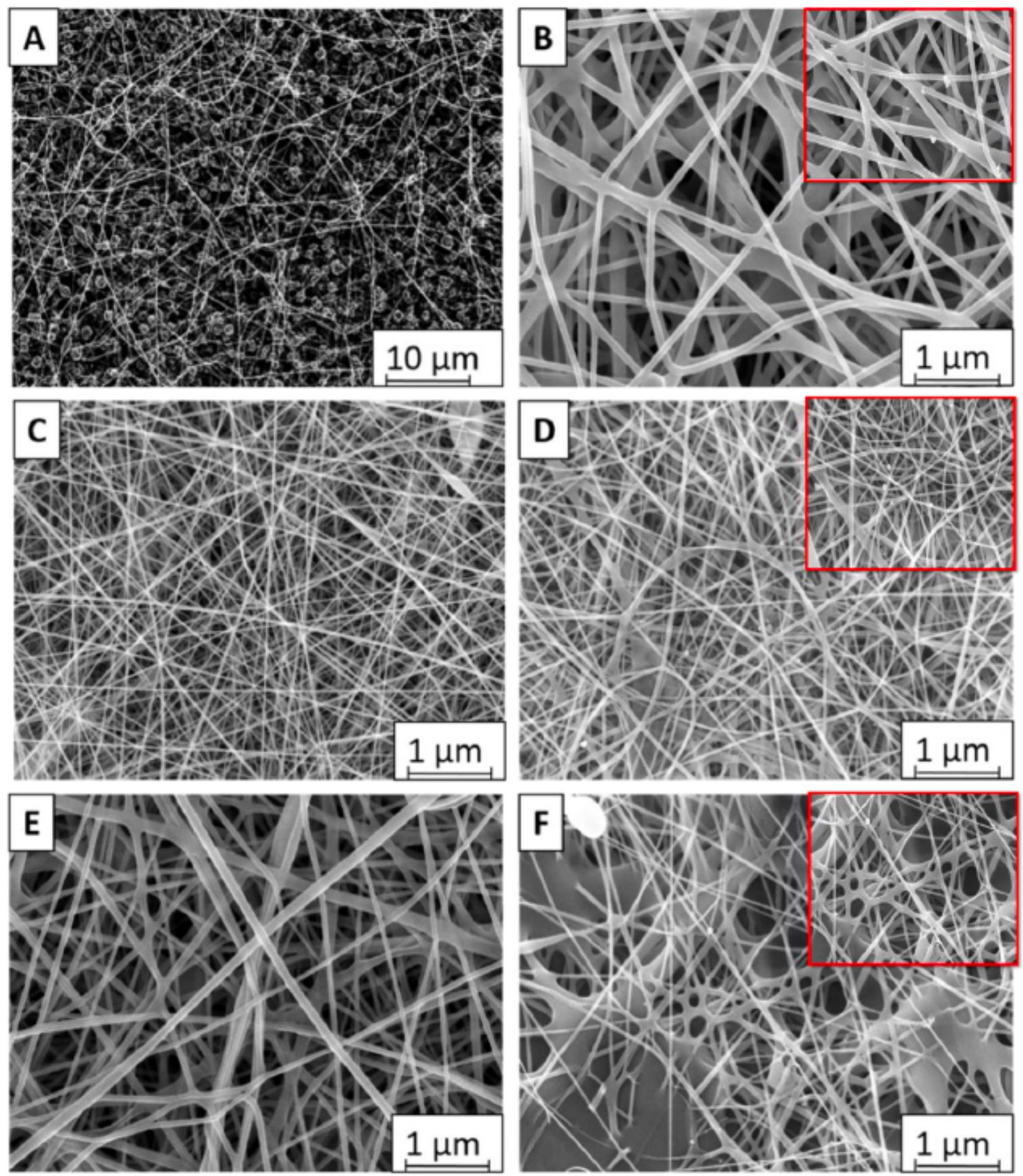

Figure 3

SEM micrographs of A.PVA, B.PVA/FA, C.PVA-Gel, D.PVA-Gel/FA, E.PVA-Alg and F.PVA-Alg/FA nanofibers. $(3 \mathrm{kX})$. 
A)

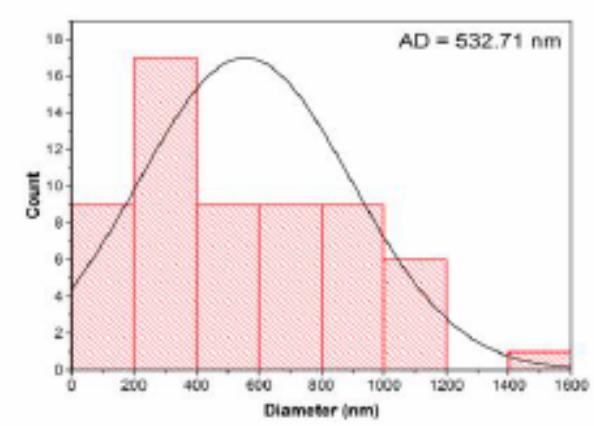

C)

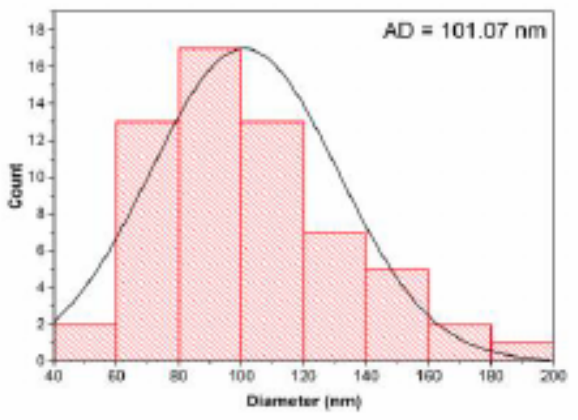

E)

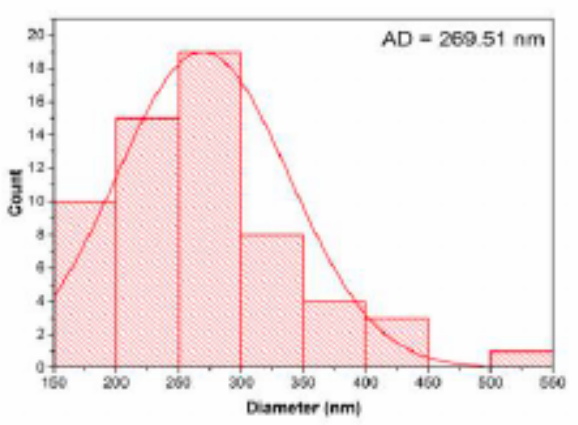

B)

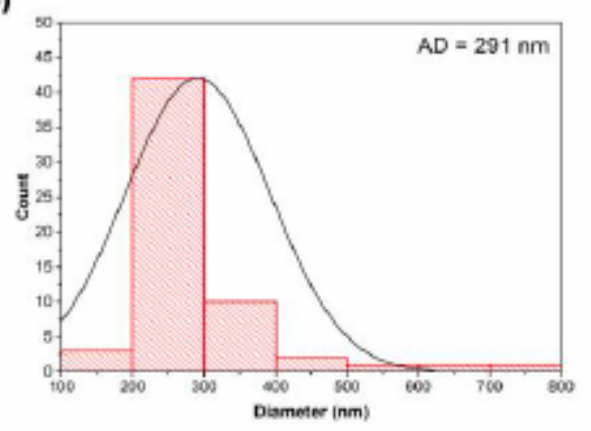

D)

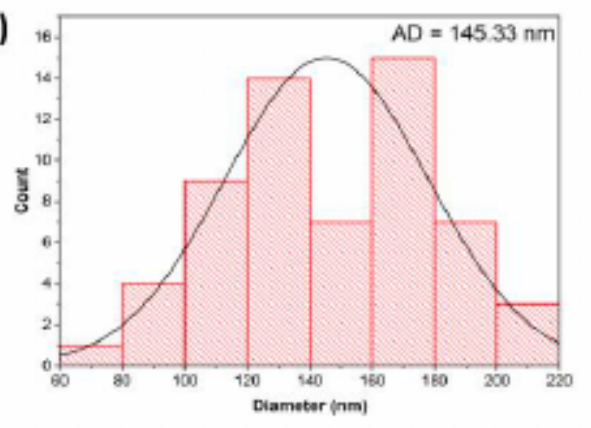

F)

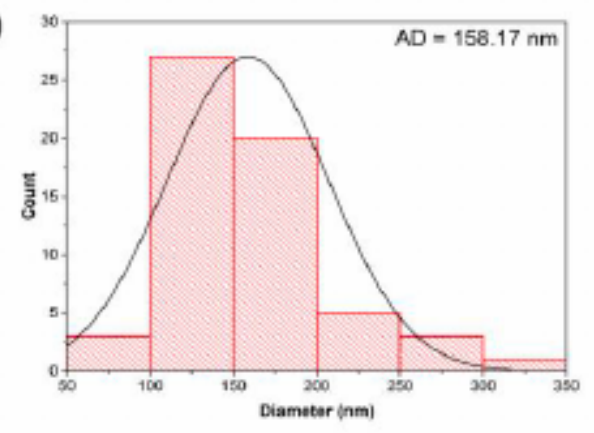

\section{Figure 4}

The average fiber diameters of A.PVA, B.PVA/FA, C.PVA-Gel, D.PVA-Gel/FA, E.PVA-Alg and F.PVA-Alg/FA fibers. 

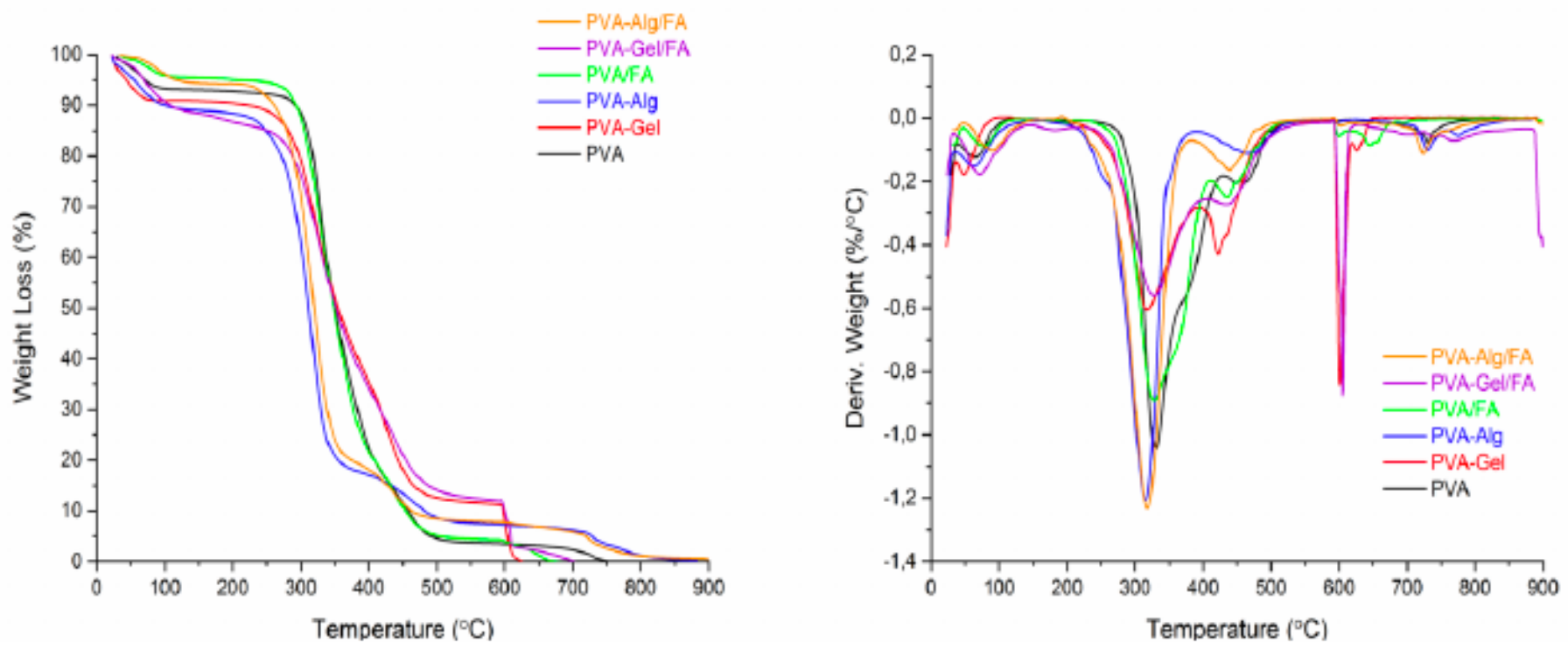

Figure 5

TGA and DTG thermograms of nanofibers.

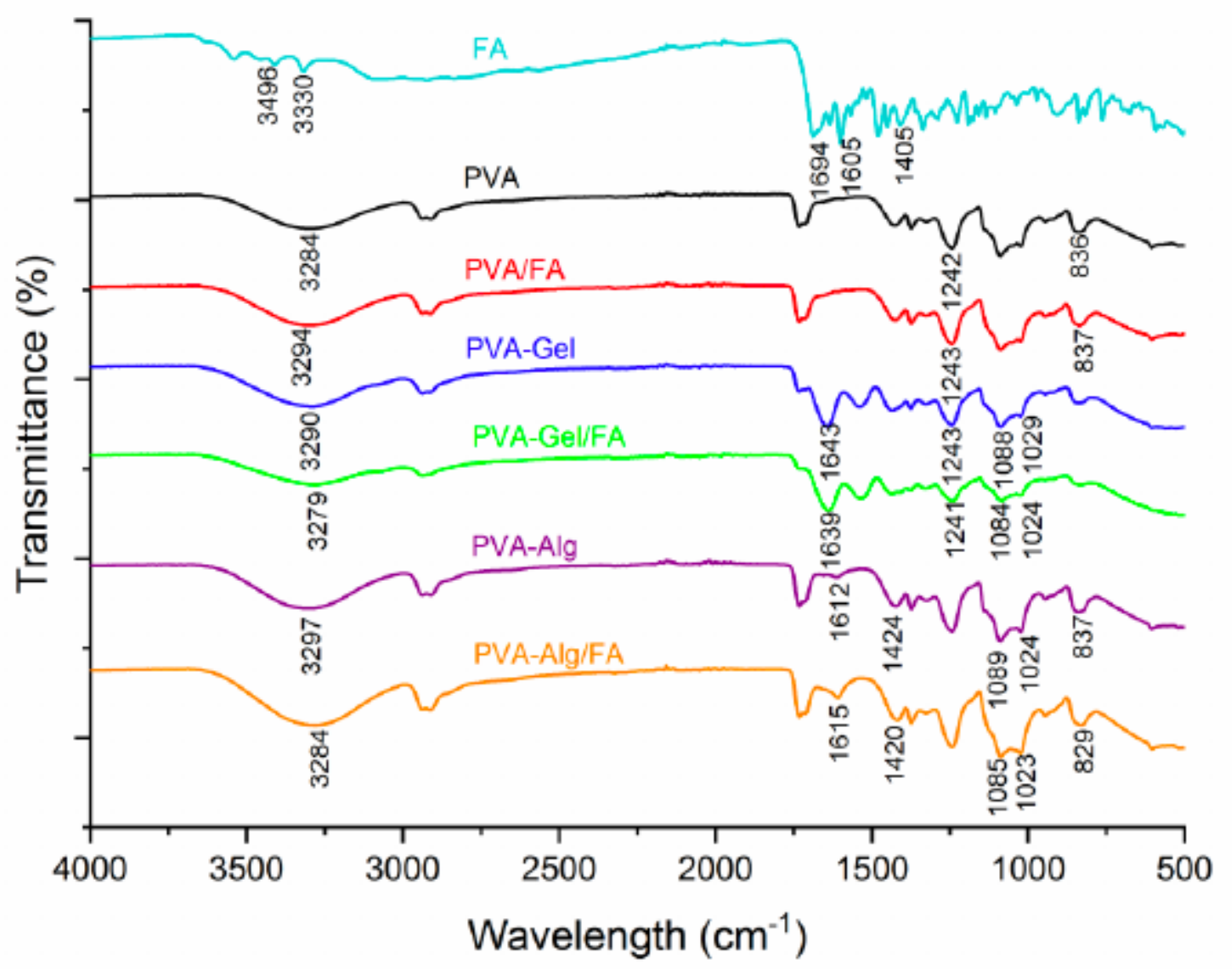

Figure 6 
FT-IR spectra of nanofibers.

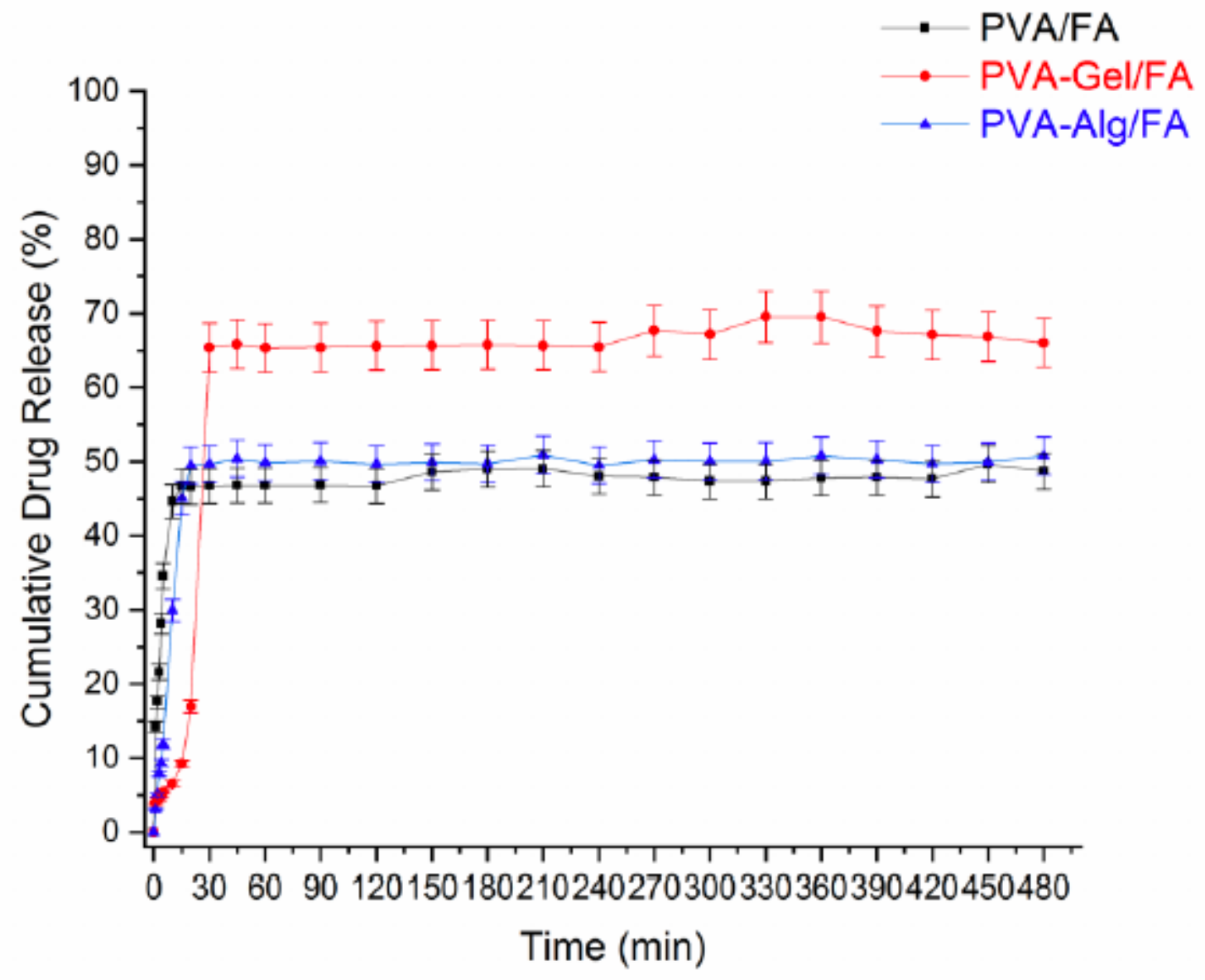

Figure 7

FA release profiles of nanofibers. 


\section{Cytoxicity of nanofibers by MTT assay}

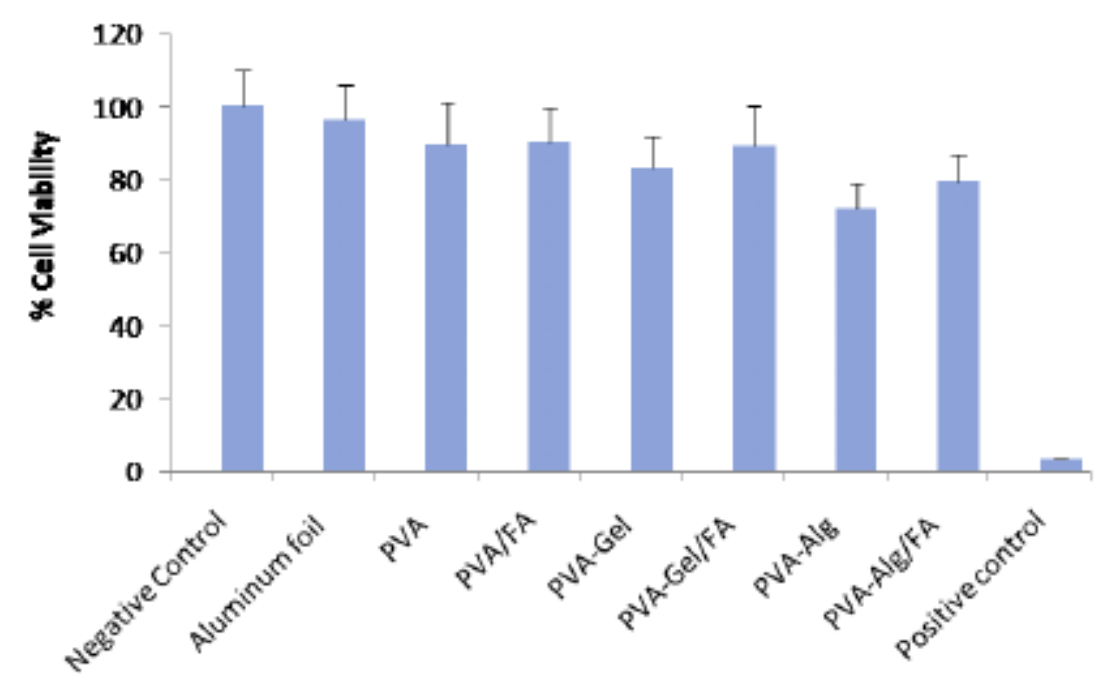

Figure 8

Effects of PVA nanofiber extract solutions on cell viability of L929 cells by MTT assay. Results were expressed as themean percentage of cell growth inhibition from 3 independent experiments. Cell viability was plotted as percent of control (assuming data obtained from the absence of nanofiber as $100 \%$ ).

\section{Cytoxicity of nanofibers by NRU assay}

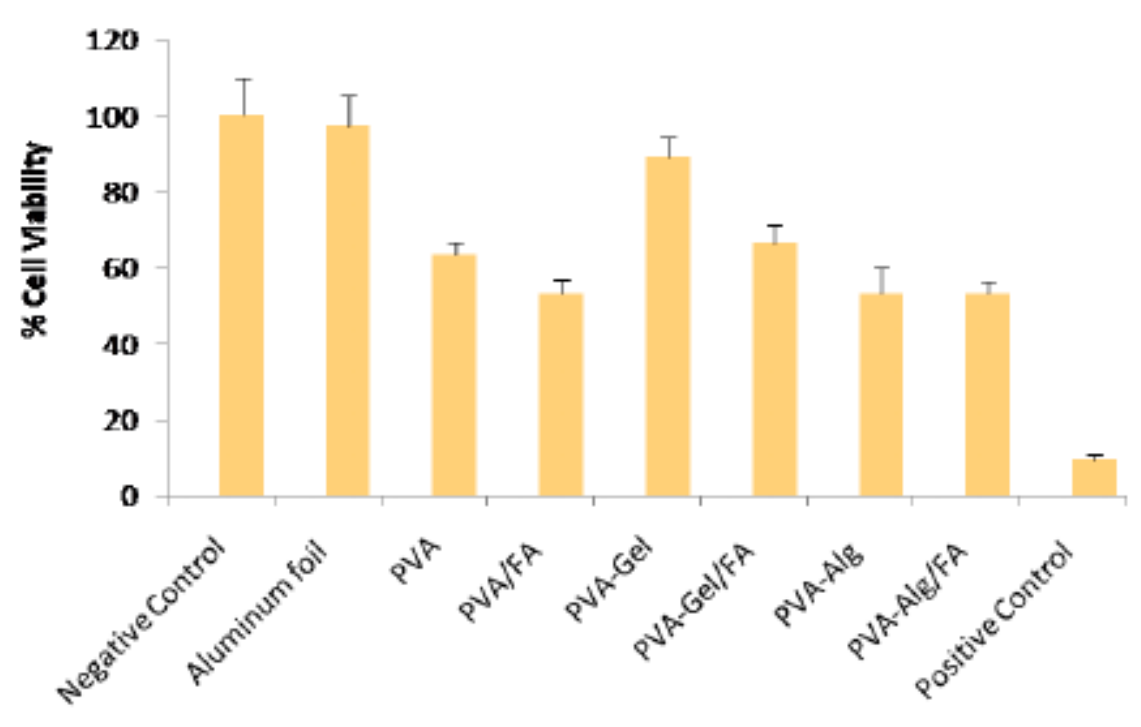

Figure 9 
Effects of PVA nanofiber extract solutions on cell viability of L929 cells by NRU assay. Results were expressed as themean percentage of cell growth inhibition from 3 independent experiments. Cell viability was plotted as percent of control (assuming data obtained from the absence of nanofiber as $100 \%$ ). 